\title{
Falcon Nest Occupancy and Hatch Success Near Two Diamond Mines in the Southern Arctic, Northwest Territories
}

\author{
Utilisation des nids et succès d'éclosion chez les faucons nichant près de \\ deux mines de diamants dans le Bas-Arctique, Territoires-du-Nord-Ouest
}

\author{
Daniel W. Coulton ${ }^{1}$, John A. Virgl ${ }^{1}$ and Colleen English ${ }^{2}$
}

\begin{abstract}
Sensitivity to anthropogenic disturbance in conjunction with slow population recovery has raised conservation concerns over impacts to raptor species from industrial development in pristine areas of their North American breeding range. We evaluated whether the presence of two diamond mines resulted in negative effects to nest use and hatch success of breeding falcons in the southern Arctic barren-grounds of the Northwest Territories. A total of 20 nest sites of Peregrine Falcon (Falco peregrinus) and Gyrfalcon (Falco rusticolus) breeding within $26 \mathrm{~km}$ of the Diavik and Ekati diamond mines were monitored annually during 1998 to 2010 . The objective of the study was to test the effects of distance from mines, relative nest age, rainfall, small mammal abundance, and mine activity levels on nest occupancy and hatch rates. Model selection results indicated that nests that were older were more likely and consistently used than nests that were established more recently. A decrease in nest use associated with the mines was not detected. Hatch success was best explained by a positive association with distance from development and a negative trend over the study period, however, these effects were weak. Hatch success of nests within and beyond an estimated $5.9 \mathrm{~km}$ distance threshold was similar, and for nest sites within this distance was unrelated to annual changes in accumulated mine footprint area through time. Hatch success for nest sites near Diavik was unrelated to changes in this mine's activity through time. Although natural and anthropogenic effects were generally weak, the lines of evidence suggested that the observed patterns were more likely the result of natural factors operating at a regional scale than more localized effects from the activity of two diamond mines.
\end{abstract}

RÉSUMÉ. Les répercussions du développement industriel dans des secteurs vierges de l'aire de nidification de rapaces en Amérique du Nord ont soulevé des préoccupations de conservation chez ce groupe d'oiseaux en raison de leur sensibilité aux perturbations anthropiques et du lent rétablissement de leurs populations. Nous avons évalué si la présence de deux mines de diamants avait des effets négatifs sur l'utilisation des nids et le succès d'éclosion des faucons qui nichent dans la toundra du Bas-Arctique des Territoires-du-Nord-Ouest. À cette fin, vingt sites de nidification de Faucon pèlerin (Falco peregrinus) et de Faucon gerfaut (Falco rusticolus) situés dans un rayon de $26 \mathrm{~km}$ des mines de diamants Diavik et Ekati ont été suivis de 1998 à 2010. L'objectif de cette étude était de tester les effets de la distance des nids aux mines, de l'âge relatif des nids, des précipitations, de l'abondance des petits mammifères et de l'intensité de l'activité minière sur l'utilisation des nids et le succès d'éclosion. Les résultats de la sélection de modèles ont indiqué que les nids les plus vieux avaient vraisemblablement plus de chance d'être utilisés et l'étaient plus régulièrement que les nids construits plus récemment. Aucune baisse de l'utilisation des nids attribuable à la présence des mines n'a été détectée. L'association positive avec la distance au développement était le facteur qui expliquait le mieux les variations du succès d'éclosion, lequel a aussi présenté une tendance négative au cours de la période de l'étude, mais ces effets étaient peu importants. Le succès d'éclosion des nids situés en deçà et au-delà d'un seuil de 5,9 km de distance était semblable; de plus, pour les sites de nidification situés à l'intérieur de ce rayon, le succès n'était pas lié aux changements annuels de l'empiétement du territoire par les mines avec le temps. Le succès d'éclosion des nids situés près de la mine Diavik n'était pas associé aux changements temporels de l'activité minière. Bien qu'en général les effets naturels et anthropiques étaient peu importants, l'ensemble des indices laisse croire que les tendances observées semblent davantage associées à des facteurs naturels agissant à l'échelle régionale qu'à des effets plus localisés de l'activité de ces deux mines de diamants.

Key Words: Arctic; development; falcons; mine; nest success; occupancy; sensory disturbance

${ }^{1}$ Golder Associates Ltd., ${ }^{2}$ Diavik Diamond Mines Inc.

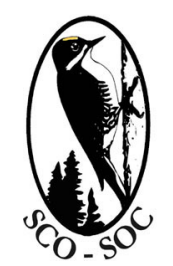

Sponsored by the Society of Canadian Ornithologists and Bird Studies Canada Parrainée par la Société des ornithologistes du Canada et Études d'oiseaux Canada

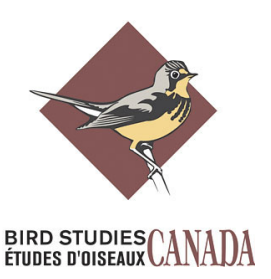




\section{INTRODUCTION}

The Arctic barren grounds represent a large and relatively undisturbed expanse of the breeding range of North American birds of prey, i.e., falcons, eagles, hawks, and owls. This area also has economically viable reserves of natural resources such as natural gas, oil, and minerals, which have been targeted for industrial development. The barren grounds in the Northwest Territories experienced an influx of mineral resource exploration during the mid-1990s that has led to the presence of several mines. Because breeding birds of prey are sensitive to human (White and Thurow 1985, Kaisanlahti-Jokimäki et al. 2008) and development disturbance (Bednarz 1984, Holthuijzen et al. 1990), monitoring their responses to industrial development is important for their conservation and maintaining population health. For these reasons, effects monitoring of falcons has been a requirement of the regulatory process.

The tundra Peregrine Falcon (Falco peregrinus) is currently designated as Special Concern under the Federal Species at Risk Act (Government of Canada 2002), and has not yet been assessed under the most recent Northwest Territories Species at Risk Act (GNWT 2012). The breeding distribution of Peregrine Falcons and other birds of prey species overlap with areas of Arctic Canada where mines have been developed. Declines of birds of prey populations elsewhere in North America have been attributed to human activities and development of infrastructure such as accommodation and other commercial buildings and road and airport expansion (Craighead and Mindell 1981). This type of response has led to conservation concerns about how local and regional breeding falcon populations and species at risk might respond to industrial development in the Arctic barren grounds but empirical results for falcons in northern Canada are lacking.

Human activities can cause direct and indirect impacts to nesting birds of prey (Richardson and Miller 1997). Land clearing associated with mines and other development infrastructure results in a "footprint," an area of direct physical alteration of habitat quality such as removal of vegetation, altered natural drainage, or changes to other attributes of the landscape. Habitat quality may also be influenced indirectly by sensory disturbance within a zone of influence (ZOI; Johnson et al. 2005, Boulanger et al. 2012). Sensory disturbance reflects how organisms perceive habitat quality in the presence of unnatural or new environmental cues such as the presence of people, sounds, lights, smells, and fugitive dust associated with development construction and operation. The effect of these types of disturbances diminishes with increasing distance from the point source. Thus, the ZOI is the spatial extent at which organisms change their behavior or distribution relative to the source of disturbance (BenítezLópez et al. 2010, Polfus et al. 2011, Boulanger et al. 2012). Once a ZOI has been established, it can then be applied to other similar and unmeasured developments to assess the cumulative direct and indirect changes to habitat across species ranges. Prior studies of birds of prey indicate that development sensory disturbance results in lower use and productivity of nests (Bednarz 1984, Holthuijzen et al. 1990) within $2 \mathrm{~km}$ of the source (Benítez-López et al. 2010). For example, indirect effects can reduce the likelihood of a successful hatch by changing parental behavior, reducing the amount of time spent foraging, or increasing energetic expenditure (Palmer et al. 2003).

In addition to anthropogenic disturbance, natural factors are also known to influence birds of prey nest use and productivity. The severity of weather during the incubation and nestling periods has been shown to decrease breeding success of birds of prey in the Arctic (Court et al. 1988, Poole and Bromley 1988, Bradley et al. 1997, Anctil 2012). Variation in the abundance of prey populations, such as songbirds or small mammals, can also strongly influence the selection of territories and productivity levels by falcons (Steenhof et al. 1999). As well, habitat suitability and how long nest sites have been established is important to the likelihood and variability of use through time for Peregrine Falcons (Wightman and Fuller 2006). For example, Wightman and Fuller (2006) found that nest sites with higher and abrupt changes in elevation with open views and that were more isolated were more likely to be used and less variable in use through time but that site quality was largely unrelated to mean productivity. These authors also demonstrated that older nests were more consistently used through time and were positively correlated with site quality based on long-term productivity.

The objective of this study was to evaluate whether sensory disturbance from the presence of industrial development in a remote area of the Canadian Arctic has resulted in adverse changes to nest occupancy and hatch success of breeding falcons (Peregrine Falcons and Gyrfalcons [Falco rusticolus]). We recognize differences in biology and diet occur among falcon species but this should not preclude using a species guild to examine indirect effects from sensory disturbance (e.g., Ammon and Stacey 1997, Aitken et al. 2002, Pavel 2004, Kirk et al. 2011). A set of a priori predictions based on previous findings in falcons and other birds of prey were considered to meet the study objective. For the effect of sensory disturbance we predicted that nest use and production of nestlings would be positively correlated with distance from development. For natural factors, we predicted that breeding season rainfall from storms would have a negative effect on nest occupancy and hatch success, whereas nest occupancy and success would be positively influenced by increased availability of prey. We also predicted that nest occupancy would be positively correlated and less variable with nest site quality and at older nests. To evaluate these predictions, we considered evidence from multiple sources including the (1) relative influence of natural versus mine-related factors on falcon use and hatch success of nest sites; and (2) relationship 
between mine activity level and hatch success of nests near development. The results from this study will increase confidence in impact predictions by filling an information gap for future environmental assessments, and falcon conservation plans as further Arctic resource development is considered.

\section{METHODS}

\section{Study area}

The Lac de Gras (LDG) study area covers $5933 \mathrm{~km}^{2}$ in the Southern Arctic Ecozone (Ecological Stratification Working Group 1998) and is located approximately $300 \mathrm{~km}$ northeast of Yellowknife, Northwest Territories (Fig. 1). Numerous lakes of varying size are distributed throughout the LDG study area and falcon nesting habitat includes bedrock cliffs up to $40 \mathrm{~m}$ high and occasional small stands of spruce (Picea spp.). During this study, the Ekati and Diavik diamond mines were owned and operated by BHP Billiton Diamonds Inc. and Diavik Diamond Mines Inc., respectively, and located in the LDG area. Both companies use open-pit mining techniques. Construction of the Ekati Diamond Mine commenced in 1997 and the processing of kimberlite ore began in 1998. The Diavik Diamond Mine was constructed from 2001 to 2002 and began operations in 2003. By December 2010, the physical disturbance footprints for Ekati and Diavik were $30.0 \mathrm{~km}^{2}$ and $9.8 \mathrm{~km}^{2}$, respectively. General site infrastructure at each mine includes a staff accommodation complex, roads, ore processing facilities, processed ore piles and containment facilities, and an airstrip. Up to 1042 employees have been present at each mine site with peak numbers occurring during construction and fewer required for operations.

\section{Nest occupancy and hatch success}

Searches and identification of falcon nest sites were initiated in 1995 and completed by helicopter during baseline studies for the environmental assessment of the Ekati Diamond Mine. Searches for nest sites targeted areas of highly suitable habitat including terrain with cliffs, steep slopes, and stands of trees. Monitoring of nest sites for use (occupancy) and nestlings (hatch) began in 1998 and were timed in accordance with reproductive chronology of species in the region (Poole and Bromley 1988). New nest sites identified during nest surveys and during weekly (April to October) and larger scale surveys for caribou, grizzly bears, and wolves, were sequentially included in the monitoring program. Although larger-scale surveys were designed around the focal species, observers recorded all species encountered including birds of prey and nest sites. By 2008, a total 20 known nest sites were identified in the study area although in some years nests were not surveyed (Table 1). Species included Peregrine Falcon $(n=$ 118 nests-years) and Gyrfalcon ( $n=20$ nest-years). Nests occupied by Rough-legged Hawk (Buteo lagopus, $n=11$ nestyears) have also been observed but were not considered for analysis and assumed to be unavailable to Peregrine or Gyrfalcons given the overlap in nesting chronology in the region (Poole and Bromley 1988). Nest locations have ranged from 0.4 to $25.5 \mathrm{~km}$ from either mine (Fig. 1). Nest site occupancy was determined by experienced biologists through visual observation of one or two adults exhibiting territorial behavior, the presence of eggs, or at least a single adult exhibiting nesting behavior. Hatch fate was determined by the presence of young (hatchlings or fledglings). Causes of nest failure could not be determined during surveys but could include predation by other birds of prey such as Bald Eagle (Haliaeetus leucocephalus), Golden Eagle (Aquila chrysaetos), or Rough-legged Hawk, meso-mammal predators such as Arctic (Vulpes lagopus) and red fox (Vulpes vulpes), or nest abandonment by adults.

At Ekati, surveys for nest occupancy and hatch success occurred at three schedules. In 1998, surveys occurred on 28 June and 13 August. In 1999, one survey was completed on 25 July. From 2000 to 2010 surveys of all nest sites were standardized to occur in the spring between 27 May and 7 June to determine which falcon sites were occupied, and then all sites were visited again between 22 and 24 July to determine hatch success. Sites that were unoccupied during the spring, but were occupied during the summer were designated as occupied so that occupancy was not conditional on detection during the spring survey. Thus, it was assumed that nest initiation occurred after the spring survey ( $n=10$ sites from 2000 to 2009). Nest occupancy data prior to 2000 were not included in occupancy analyses because late season surveys would likely have missed occupied nests that failed before the survey date but these data were included in the analyses of hatch success.

At Diavik, from 2000 to 2003, surveys for nest site occupancy and hatch success were completed from 22 to 24 July. From 2004 to 2010, spring surveys for nest site occupancy were completed during 29 May to 7 June, and all sites were revisited from 22 to 26 July to determine hatch success. Because nest site monitoring by Diavik prior to 2004 would likely underestimate occupancy rates (birds that abandoned nests earlier in the season are missed), these data were not included in the occupancy analysis but were included in the analyses of hatch success.

\section{Natural factors}

Nest sites located on high and isolated cliffs are considered to be of high suitability for Peregrine Falcons and other bird of prey species (Court et al. 1988, Poole and Bromley 1988, Wightman and Fuller 2006) because they offer protection from weather, nest predators, and reduced competition (Wightman and Fuller 2006). Many of the nest sites in the LDG study area occur on cliffs that overlook lakes. To assess the suitability of nest sites in the study area, nest locations were intersected with GIS raster layers of Canadian digital elevation (Natural Resources Canada 2001) and supervised land classification data that described deep water from satellite imagery 
Fig. 1. Location of raptor nest sites monitored in the Lac de Gras study area, Northwest Territories, Canada from 1998 to 2010.

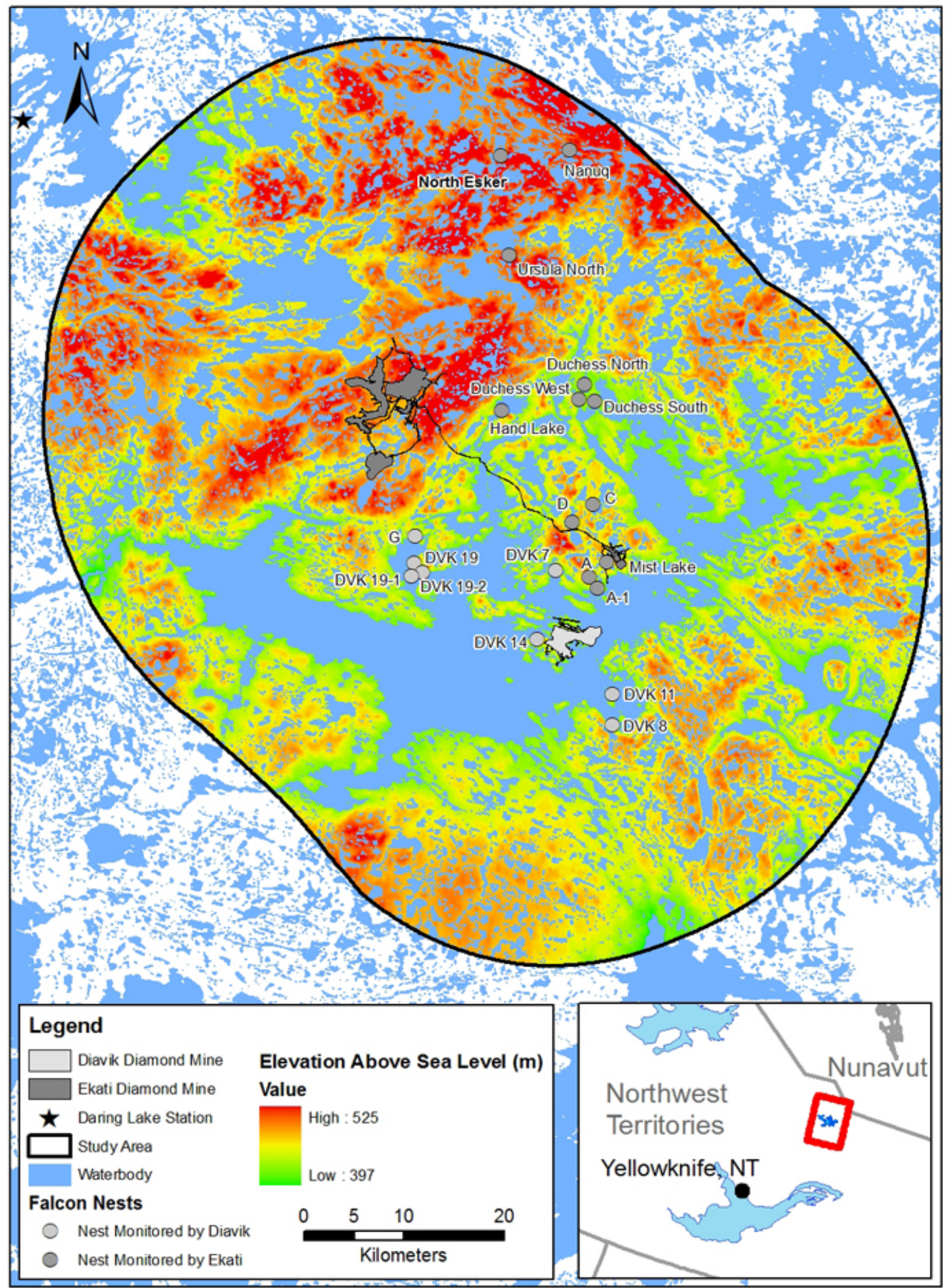




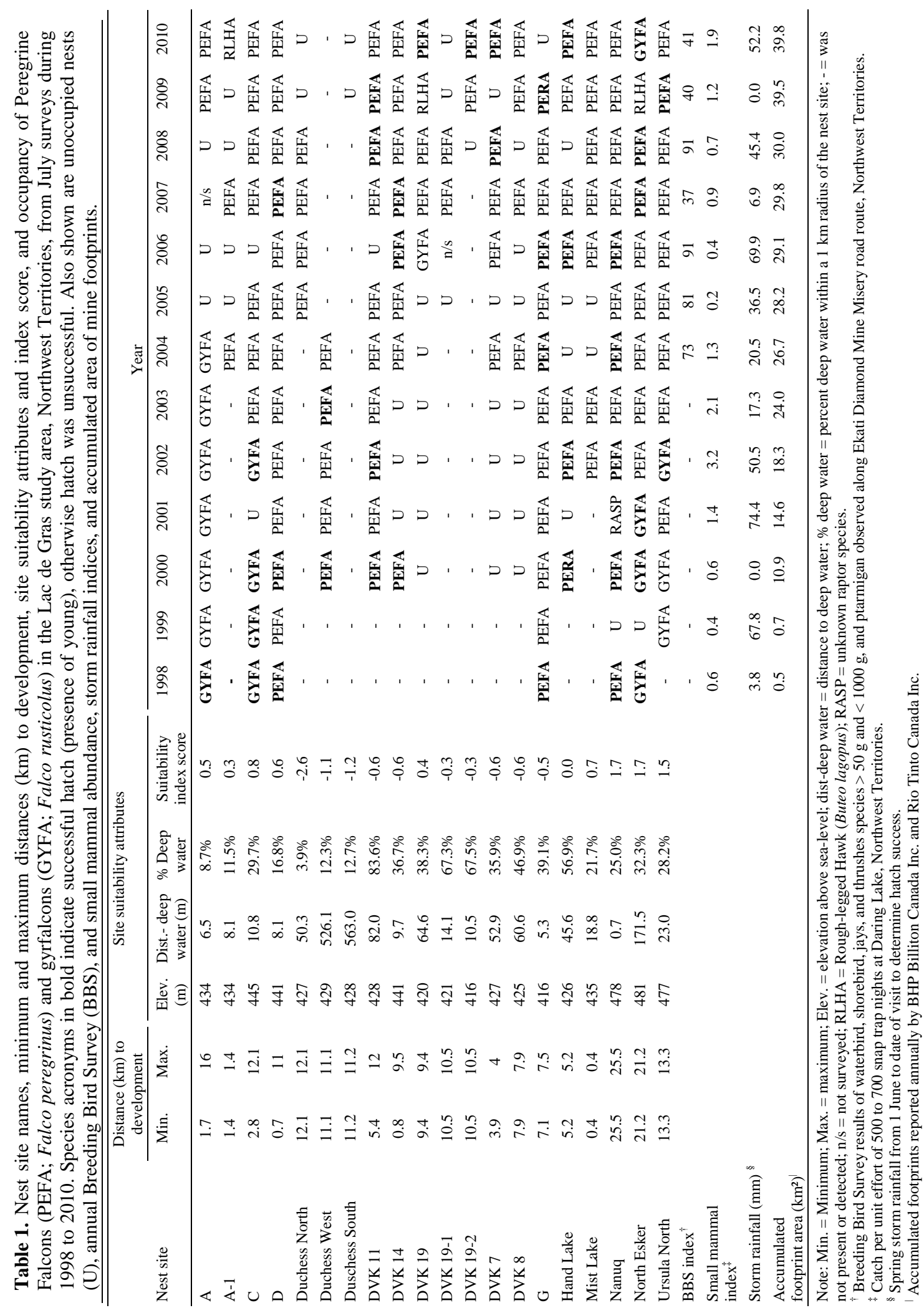


(Matthews and Epp 2001). The horizontal accuracy was 25 to $29 \mathrm{~m}$ for elevation and $30 \mathrm{~m}$ for water data, respectively. The vertical accuracy of the elevation data was 3.7 to $8.5 \mathrm{~m}$. Nest site variables of elevation (metres above sea level), distance (m) to deep water, and percent deep water within a $1 \mathrm{~km}$ radius were determined in a GIS platform using the near analysis tool in ArcGIS (V9.3, ESRI, California, USA). A $1 \mathrm{~km}$ radius was used to consider suitability at a scale beyond the nest site and to capture the presence of larger lakes occurring throughout the study area that would provide sites with open views. Presumably open views are important to isolate nests from conspecific intruders and mammalian predators as postulated by Whiteman and Fuller (2005) or may provide windier conditions that aid flight. The combination of these variables was interpreted to describe gradients of elevation, elevation gain, and the isolation of suitable nest sites in the study area. To validate the use of these variables as cues used for nest site selection, values of these variables were also determined for and compared to randomly selected sites $(n=200)$ that occurred over land and were a minimum of $2 \mathrm{~km}$ apart to account for neighboring territories (Wightman and Fuller 2005, 2006).

The historical age of nest sites can influence the likelihood and consistency of use by peregrine falcons where older nests are more consistently occupied and productive over the long term than nests more recently established (Wightman and Fuller 2006). We used year of initial detection of nests as an index of how long a nest had been established in the study area. Thus, nests that were detected earlier in the study were considered more established and assumed to be of higher suitability than those nests that were detected more recently.

To assess the influence of weather, a rainfall index was included in occupancy and hatch success models based on measurements from the Ekati weather station, 1998 to 2003, and the Diavik weather station, 2004 to 2010. In the occupancy analysis, accumulated rainfall from 1 to 31 May was included as the prenesting rainfall variable. For the hatch success analysis, the total amount of rain that fell during storms was used as an index of the severity of weather. A storm was defined as two or more consecutive days of rainfall from 1 June 1 through the date of the summer nest site visit (Bradley et al. 1997). Rainfall data were not available for May 2001, so this year was censored from the occupancy analysis.

Peregrine diet preferences indicate that medium-sized ( $>50$ $\mathrm{g},<1000)$ waterbirds, shorebirds, jays, and thrushes are preferred avian prey (Dawson et al. 2011). The Ekati mine has participated in the North American Breeding Bird Survey (BBS) by completing point-counts at 50 stations along the length of the Misery road in June since 2004. An annual relative abundance index of medium-sized bird species in these guilds was tabulated from the results of the BBS (Table 1). Although not a primary source of diet, there is also evidence that Peregrine Falcons consume small mammals (Court et al 1988, Bradley and Oliphant 1991, Dawson et al. 2011). The Government of the Northwest Territories, Department of Environment and Natural Resources (ENR) has monitored small mammal abundance at Daring Lake, NWT, located approximately $50 \mathrm{~km}$ west from Ekati and $75 \mathrm{~km}$ northwest of Diavik. A relative small mammal abundance index was generated from snap trap sampling completed during July and August from 1998 to 2010 (ENR, unpublished data). Small mammal species sampled included red-backed voles (Myodes rutilus), meadow voles (Microtus pennsylvanicus), brown lemmings (Lemmus trimucronatus), and collared lemmings (Dicrostonyx groenlandicus). Additional details on methods used to generate small mammal indices are not presented but are available at ENR's website (http://www.enr.gov.nt.cal _live/pages/wpPages/survey_protocols.aspx).

\section{Anthropogenic factors}

Annual and spatial data specific to sources of sensory disturbance (e.g., fugitive dust, blasting, lights, noise, and smells) were not available for either mine site. We used distance from the nest site to mine footprints to provide an ecologically relevant surrogate of the effect from particular sources of disturbance on biological metrics (Johnson et al. 2005, Wier et al. 2007, Benítez-López et al. 2010, Boulanger et al. 2012). The distance in kilometers $(\mathrm{km})$ from a nest site to the nearest point of the physical footprint of the Ekati or Diavik mines for each year was measured to account for changes in the size of footprints through time. Distances were measured using the near analysis tool in ArcGIS (V9.3, ESRI, California, USA). In addition to a distance variable, sensory disturbance levels are expected to be positively correlated with the number of employees at site because staff levels at site are correlated with more flights to site, blasting, noise, fugitive dust, and general activity. The maximum monthly number of full-time employees at Diavik from 2003 to 2010 during the falcon breeding season (May to August) was used as an index of sensory disturbance from mine activity (range: 286 to 1042 full-time employees). Historical employment data for Ekati were not available. Noise modeling at Diavik predicted that sound from jet aircraft would attenuate to background levels at a distance of $7 \mathrm{~km}$ and represents the greatest spatial extent of any potential source of sensory disturbance including dust, (Diavik Diamond Mines Inc., unpublished manuscript). Therefore, in the absence of a ZOI derived from the falcon occupancy or hatch success data, we assumed the success of nests within $7 \mathrm{~km}$ of Diavik would be negatively correlated with values of maximum numbers of monthly employees at this mine.

\section{Statistical analysis}

Nest site selection and suitability index

Because the data were limited to 20 nest sites, we combined individual nest site suitability variables of elevation (metres 
above sea level), distance ( $\mathrm{m}$ ) to deep water, and percent deep water within a $1 \mathrm{~km}$ radius into a single index using principal components analysis to maintain reduced model structure. Principal components were developed from the attribute values of random nest site locations. The relative importance of each principal component (PC) was assessed using the broken-stick method in which PC eigenvalues that exceed those corresponding to a random broken-stick distribution are considered interpretable because they explain more variation than by chance (Jackson 1993). A relative measure of PC to broken-stick eigenvalues greater than 1.0 were considered interpretable. The first interpretable PC was used to predict PC scores of observed nest sites.

The first principal component (PC1) and second principal components (PC2) explained $51.3 \%$ and $29.0 \%$ of the variance in elevation above sea level, distance to deep water, and percent deep water within $1 \mathrm{~km}$ for random sites, respectively. The PC1 and PC2 structural coefficients for elevation above sea level, distance to deep water, and percent deep water within $1 \mathrm{~km}$ of the site were $-0.51,-0.55$, and 0.66 and $0.75,-0.66$, and 0.03 , respectively. The relative measure of eigenvalues of PC1 and PC2 to broken-stick eigenvalues were 0.86 and 1.04 , respectively. Thus, PC2 was the first component that exceeded a random eigenvalue and was deemed interpretable (brokenstick method; Jackson 1993). The PC2 axis reflected a gradient of ruggedness around the nest site in which more positive values indicated higher values of elevation above sea level, shorter distance to deep water, and greater percent deep water within $1 \mathrm{~km}$ of the site, although the scale was more heavily weighted by the first two variables. The relationships among variables comprising PC2 are generally consistent with multivariate patterns falcon nest site selection (high cliffs with open views; Wightman and Fuller 2005) and so PC2 was considered biologically meaningful. Multivariate and univariate analysis of variance were used to identify differences in site suitability variables, including PC scores, between random and observed nest sites.

\section{Nest occupancy and hatch success}

Cluster-based logistic regression was used to examine the relationships between the response variables of falcon nest occupancy and hatch success and a suite of explanatory variables. Hatch success was the probability that at least one hatchling or fledgling was present. Explanatory variables considered included study year (year), distance from mines, rainfall, and PC score (index of nest site suitability), and year of initial nest detection (relative age of the nest site under observation). Year and year of initial nest detection were included as continuous variables to assess trends. The clusterbased approach accounted for unmeasured nest site variables through a specified model correlation structure for observations at the same site through time. An autoregressive correlation structure that assumes a decrease in correlation within subjects over time was specified. This seemed reasonable because population changes through losses (mortality or emigration) and gains (recruitment or immigration) were likely to have occurred given the duration of the study and use of nest sites by both study species. Each nest site's annual occupancy and fate was weighted by the proportion of years it contributed to regression analyses (range: 0.2 to 1.0 for occupancy and 0.15 to 0.93 for hatch success) and was standardized across the candidate set of models. Thus, analyses of nest occupancy and hatch success gave heavier weighting to nests that had been monitored longer. This was done as an added layer of conservatism under the assumption that nests exposed to sensory disturbance longer would be more likely to exhibit the predicted negative effects. Because year is correlated with the rainfall index variable, additive models of these variables were not considered. To identify the spatial extent of sensory disturbance effects on nest occupancy or hatch success, a quadratic term for distance $\left(\right.$ distance $^{2}$ ) was used. This quadratic term, if supported by the data, allows for a hypothetical ZOI (Johnson et al. 2005) to be estimated from the asymptote. A second-order polynomial for year of nest detection was also considered to assess a nonlinear relationship. The candidate set of models included singular and additive combinations of these variables, and an interaction between year and nest suitability and distance variables. The global (fully saturated) model included terms for study year, distance, year of initial nest detection, rainfall, and nest suitability index. A statistical null or equal means model was also included in the candidate set of models as a benchmark for explanatory value.

The candidate set of models describing multiple working hypotheses was evaluated using Akaike's Information Criterion corrected for small sample size (AICc; Burnham and Anderson 2002). A variance inflation factor ( $\hat{c}$; Burnham and Anderson 2002) of the global model was estimated using deviance divided by degrees freedom (Littell et al. 2002) for evidence of model lack of fit (i.e., $\hat{c}>1.0$ ). To correct parameter standard errors and test statistics, the candidate model set was scaled to the square root of $\hat{c}$ (Littell et al. 2002) and a quasi-likelihood approach (QAICc; Burnham and Anderson 2002) was applied to evaluate the candidate models. Model predictions were produced using parameter estimates from the highest ranking model. Models with $\triangle \mathrm{AICc} \leq 2.0$ were generally considered when making inferences from model results, but also considered was the presence of uninformative parameters based on the relative change in AICc units because of the penalty factor of adding one more variable (i.e., penalty of $\sim 2.0$ AICc units) to the model (Arnold et al. 2010). Noncompetitive models were not considered when making inferences. Predictions of the top-ranked models for occupancy and hatch success are presented with Peregrine and Gyrfalcon (mean $\pm 95 \% \mathrm{CI}$ ) and with Peregrine (mean only) data so that additive differences between species can be 
derived visually in the presence of a low number of Gyrfalcon observations that limit detection of species effects.

Secondary analyses were completed to further evaluate predictions about natural effects on nest occupancy and hatch success. Pearson product-moment correlation was used to evaluate the relationship between year of initial nest detection and the principal component habitat suitability score and also for annual occupancy rates with BBS and small mammal indices. The same approach was used to evaluate annual hatch success rates with BBS and small mammal indices.

\section{Hatch success within a ZOI}

An assumed ZOI distance threshold was used to further evaluate negative mine-related effects to hatch success. The ZOI distance threshold assumed was either (1) estimated from a supported quadratic distance model of occupancy or hatch success data or (2) the $7 \mathrm{~km}$ determined for noise during baseline studies at Diavik if a ZOI could not be estimated from the data. Logistic analysis of variance was used to compare hatch success within and outside the assumed ZOI, and for nests within the ZOI relative to changes in accumulated footprint size of Ekati and Diavik through time. Finally, Pearson product-moment correlation was used to evaluate the relationship between Diavik employee (mine activity) levels and success of falcon nests within an assumed ZOI. Statistical analyses were completed using PROCs GENMOD, CORR, and GLM (V9.3, SAS Institute, North Carolina, USA). The MASS package (Venables and Ripley 2002) in R (V2.15.2, R Development Core Team 2012) was used for principal components analysis.

\section{RESULTS}

\section{Nest site suitability}

Variables considered as suitability attributes for observed nest sites in the study area ranged from 416 to $481 \mathrm{~m}$ above sea level, 0.7 to $563.0 \mathrm{~m}$ from deep water, and had $3.9 \%$ to $83.6 \%$ deep water within a $1 \mathrm{~km}$ radius (Table 1). The multivariate distribution of these variables differed between random and observed nest sites (MANOVA Wilks' Lambda $=0.58, F_{6,213}=$ $38.73, P<0.01)$. Relative to random sites, observed nest sites were on average $14.5 \mathrm{~m}$ (95\% CI: 5.7 to $23.4, P<0.01)$ lower in elevation, $104 \mathrm{~m} \mathrm{(95 \%} \mathrm{CI:} 36.7$ to $171.6, P<0.01)$ closer to deep water and had $14.9 \%$ (95\% CI: 8.6 to $21.1 \%, P<0.01$ ) more deep water within $1 \mathrm{~km}$ of the site.

The range of PC2 scores for observed nest sites was -2.62 to 1.94 and for random sites was -3.21 to 2.17 . Observed nest site PC2 scores were 2.35 units (95\% CI: 1.84 to $2.85, P<$ $0.01)$ higher those of random sites. The spatial distribution of PC2 scores relative to nest site distance from mine indicated that sites with above average PC2 values were located both near and far from the mines (Fig. 2). Values of PC2 scores for nest sites were negatively correlated with the year of initial detection $(r=-0.56, P=0.01, n=20$ nest sites $)$.

\section{Nest occupancy}

After censoring late season occupancy survey data prior to 2004 for Diavik and 2001 observations for Ekati when rainfall data were missing, 143 observations remained for this analysis. For nest occupancy, evaluation for lack of fit of the global model indicated no overdispersion $(\hat{c}=0.92)$ so a dispersion parameter was not included. Model selection results indicated that the most parsimonious model included a nonlinear effect for year of nest detection (Table 2). The second-ranked model contained a linear effect for year of nest detection. In terms of relative support of year of nest detection, the polynomial term had 1.3 times relative model weight $\left(\mathrm{w}_{i}\right)$ than the linear term. This effect had at least 4.0 times more support based on $\mathrm{w}_{i}$ than the balance of other effects considered in the candidate set. Of the linear variables considered, year of nest detection had at least 6.0 times greater relative $\mathrm{w}_{i}$ than did the models with site suitability index, distance, year, or rainfall. The effect for rainfall was not ranked higher than the equal means model. Selection uncertainty was evident among the candidate set of models but inferences were based on the top-ranked model. The model of quadratic distance is also presented because it provided the strongest evidence for an assumed mine-related effect.

Table 2. Model selection results for the probability of raptor nest occupancy in the Lac de Gras study area during 2000 to 2010. Shown are number of model parameters (K), Akaike's Information Criterion score (AICc) and difference from top model $(\triangle \mathrm{AICc})$, and relative model weight $\left(\mathrm{w}_{i}\right)$.

\begin{tabular}{|c|c|c|c|c|c|}
\hline Model & $\begin{array}{c}-\log \\
\text { likelihood } \\
\end{array}$ & $\mathrm{K}$ & $\mathrm{AICc}$ & $\Delta \mathrm{AICc}$ & $\mathrm{w}_{i}$ \\
\hline $\operatorname{detect}^{2}$ & -49.69 & 2 & 103.47 & 0.00 & 0.32 \\
\hline detect & -49.97 & 2 & 103.95 & 0.56 & 0.24 \\
\hline $\begin{array}{l}\text { dist }+ \text { detect }+ \text { rain }+ \text { habitat } \\
(\text { global })\end{array}$ & -47.61 & 5 & 105.66 & 2.19 & 0.11 \\
\hline dist + dist $^{2}$ & -49.82 & 3 & 105.82 & 2.35 & 0.10 \\
\hline dist + habitat & -50.15 & 3 & 106.47 & 3.00 & 0.07 \\
\hline habitat & -51.72 & 2 & 107.53 & 4.06 & 0.04 \\
\hline dist + habitat + dist $*$ habitat & -49.91 & 4 & 108.11 & 4.64 & 0.03 \\
\hline dist + year & -51.08 & 3 & 108.34 & 4.87 & 0.03 \\
\hline dist & -52.58 & 2 & 109.24 & 5.77 & 0.02 \\
\hline equal means & -54.95 & 1 & 111.94 & 8.47 & 0.00 \\
\hline
\end{tabular}

Note: detect $=$ year nest detected; detect $^{2}=$ nonlinear year nest detected term; dist $=$ distance $;$ dist $^{2}=$ quadratic distance term; rainfall $=$ accumulated rain from 1 May to 1 June; year is continuous; habitat = habitat quality inde (PC2 score); $\mathrm{K}=$ number of parameters plus 1 for an intercept; only models with $\triangle \mathrm{AICc} \leq 6.00$ are presented and the equal means and global models for reference.

Based on top-ranked models with linear effects, the logistic regression coefficient and associated statistics $( \pm 95 \% \mathrm{CI}$, parameter test statistic, $P$-value) for distance was $0.09(-0.08$ to $0.27, Z=1.04, P=0.30)$, rainfall was $-0.02(-0.05$ to 0.02 , $Z=-0.97, P=0.33)$, nest suitability index was $0.65(-0.27$ to $1.58, Z=1.39, P=0.17)$, year of nest detection was -32.98 $(-59.19$ to $-6.76, Z=-2.47, P=0.01)$, and year was $0.02(-0.12$ 
Fig. 2. Spatial distribution of nest site quality relative to distance from the Ekati and Diavik diamond mines in the Lac de Gras study area. Elevation above sea level, distance to deep water, and percent deep water within a $1 \mathrm{~km}$ radius of nest sites were considered as suitability attributes. Values for each nest site in the study were derived from the second principal component (PC2). Observation labels indicate the year the nest site was detected and monitoring began .

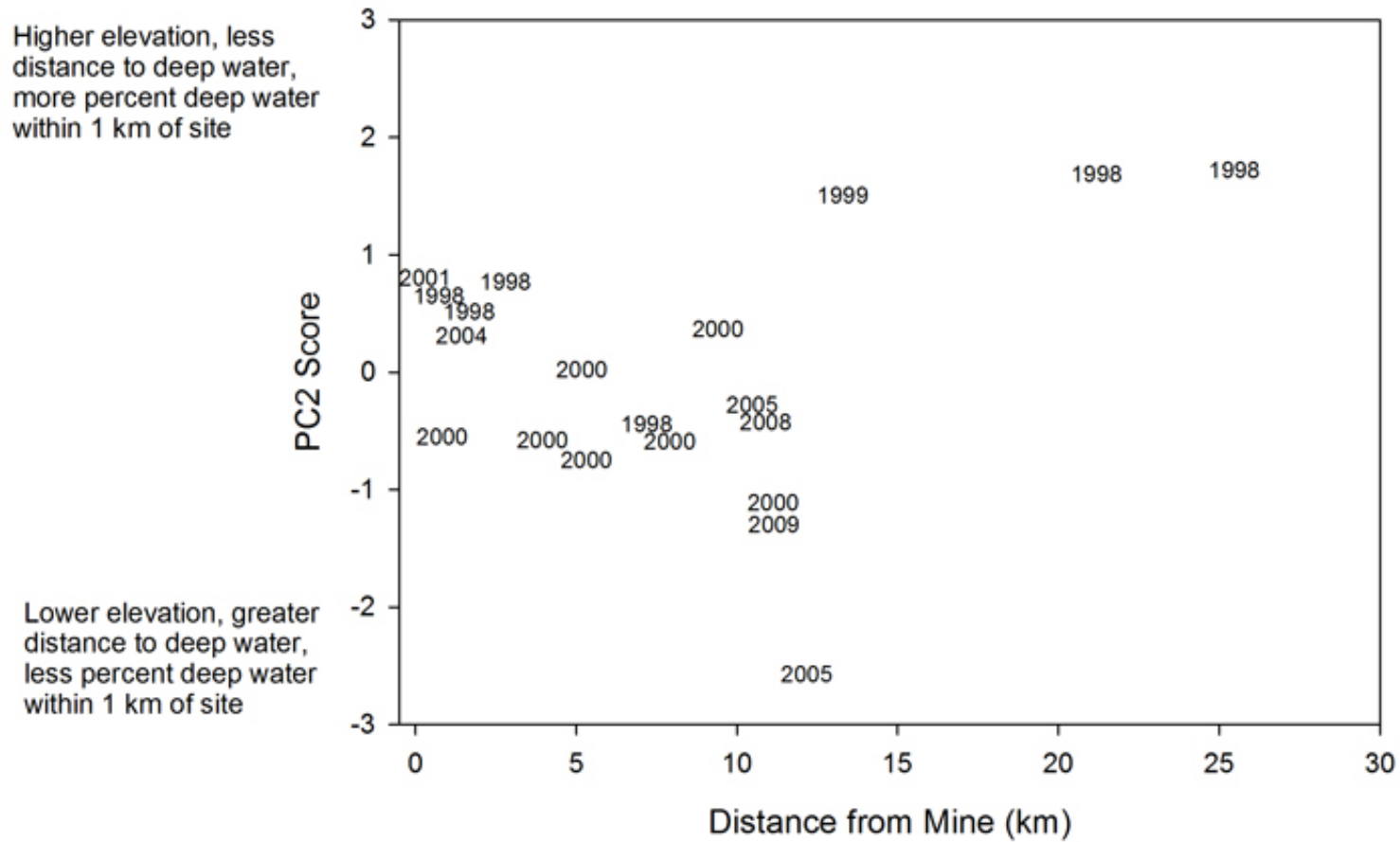

to $0.17, Z=0.30, P=0.76)$. Of the variables considered, only year of nest detection was different than zero and indicated that nest sites detected earlier during the study were more likely and consistently occupied than those detected more recently (Fig. 3a).

Although not within 2.0 $\Delta$ AICc units of the top-model, the quadratic model of distance indicated that the asymptote of the curve describing a ZOI occurred at $5.9 \mathrm{~km}$ (95\% CI: 5.6 to $6.4 \mathrm{~km}$; Fig. 3b). This model indicated that, the likelihood of nest occupancy was high near the mine footprints, lowest at $5.9 \mathrm{~km}$ from the mines, and then increased with distance from the mines to a maximum value. Correlation analysis indicated that annual occupancy rates were not significantly correlated with the BBS index $(r=-0.34, P=0.46, n=7$ years $)$ during 2004 to 2010 or with the small mammal index $(r=0.48$, $P=0.16, n=10$ years) during 2000 to 2010 .

\section{Hatch success}

Annual values of hatch success ranged from $0 \%$ in 2005 to $100 \%$ in 1998. Evaluation for lack of fit of the global model indicated overdispersion ( $c=1.24$ ) so a dispersion parameter was specified for the candidate set of models. The most parsimonious model contained linear effects for distance and year (Table 3 ). The second-ranked model contained the year effect but it was only marginally better than a model that contained only a distance effect. Of the linear variables considered, year and distance had approximately equal relative $\mathrm{w}_{i}$ and the effects for site suitability index or rainfall were not ranked higher than the equal means model. The top model predicted a decline in hatch success through time (Fig. 4a) and increased with distance from mine (Fig. 4b). A quadratic model of distance was not supported in the model selection results so a ZOI for hatch success was not estimated.

Based on top-ranked models with linear effects, the logistic regression coefficient and statistics for distance was 0.05 $(-0.01$ to $0.11, Z=1.62, P=0.10)$, rainfall was $-0.01(-0.03$ to $0.01, Z=-1.32, P=0.19)$, nest site suitability index was -0.30 $(-0.76$ to $0.17, Z=-1.24, P=0.21)$, year of nest detection was $-150.64(-586.87$ to $275.58, Z=-0.69, P=0.49)$, and of year was $-0.12(-0.26$ to $0.02, Z=-1.62, P=0.10)$. The effects of year and distance were the only variables that were likely different than zero although only marginally. The effect of year was 2.4 times greater in magnitude than the effect for distance. Annual hatch success rates were not significantly correlated with the BBS index $(r=-0.11, P=0.81, n=7$ years $)$ during 2004 to 2010 or with the small mammal index $(r=-0.07$, $P=0.81, n=13$ years) during 1998 to 2010 . 
Fig. 3. Probability predictions ( $\pm 95 \%$ CI; blue dash) of nest occupancy for Peregrine (Falco peregrinus) and Gyrfalcon (Falco rusticolus; blue line) in the Lac de Gras study area, during 2000 to 2010, based on the top ranked model (Table 2 ) for the effect of year of initial nest detection as an index of relative site age (A) and the maximum spatial extent of sensory disturbance (zone of influence; ZOI) estimated from exposure to two mines (B). Also shown are raw binomial observations (circles) by distance and the predictions for Peregrine Falcon (red line).
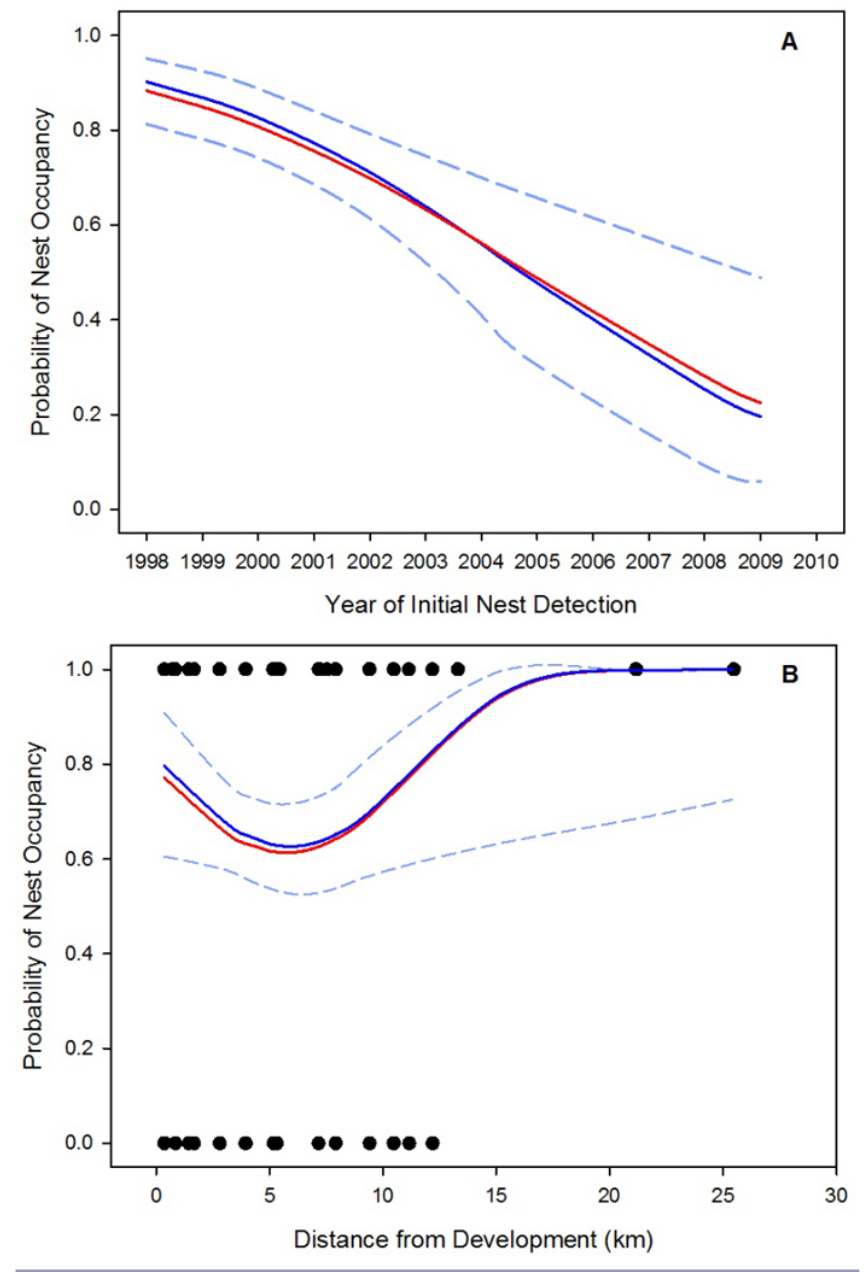

Hatch success within a ZOI

A supported ZOI threshold of $5.9 \mathrm{~km}$ was estimated from occupancy data and assumed for examinations of hatch success. Based on the top-ranked model of hatch success, nests occurring within the ZOI did not differ in hatch success from those outside the ZOI after controlling for the effect of year $(\beta=0.77, S E=0.60, Z=1.27, P=0.20$ ). The effect of annual changes in the combined footprint size of the mines on hatch
Fig. 4. Probability predictions ( $\pm 95 \%$ CI; blue dash) of nest hatch for Peregrine (Falco peregrinus) and Gyrfalcon (Falco rusticolus; blue line) in the Lac de Gras study area, during 1998 to 2010, based on the top ranked model (Table 3) for the effects of year (temporal trend; A) and distance (B). Shown is the mean response after controlling for other model effects. Also shown are raw binomial observations (circles) by distance and the predictions for Peregrine Falcon (red line).
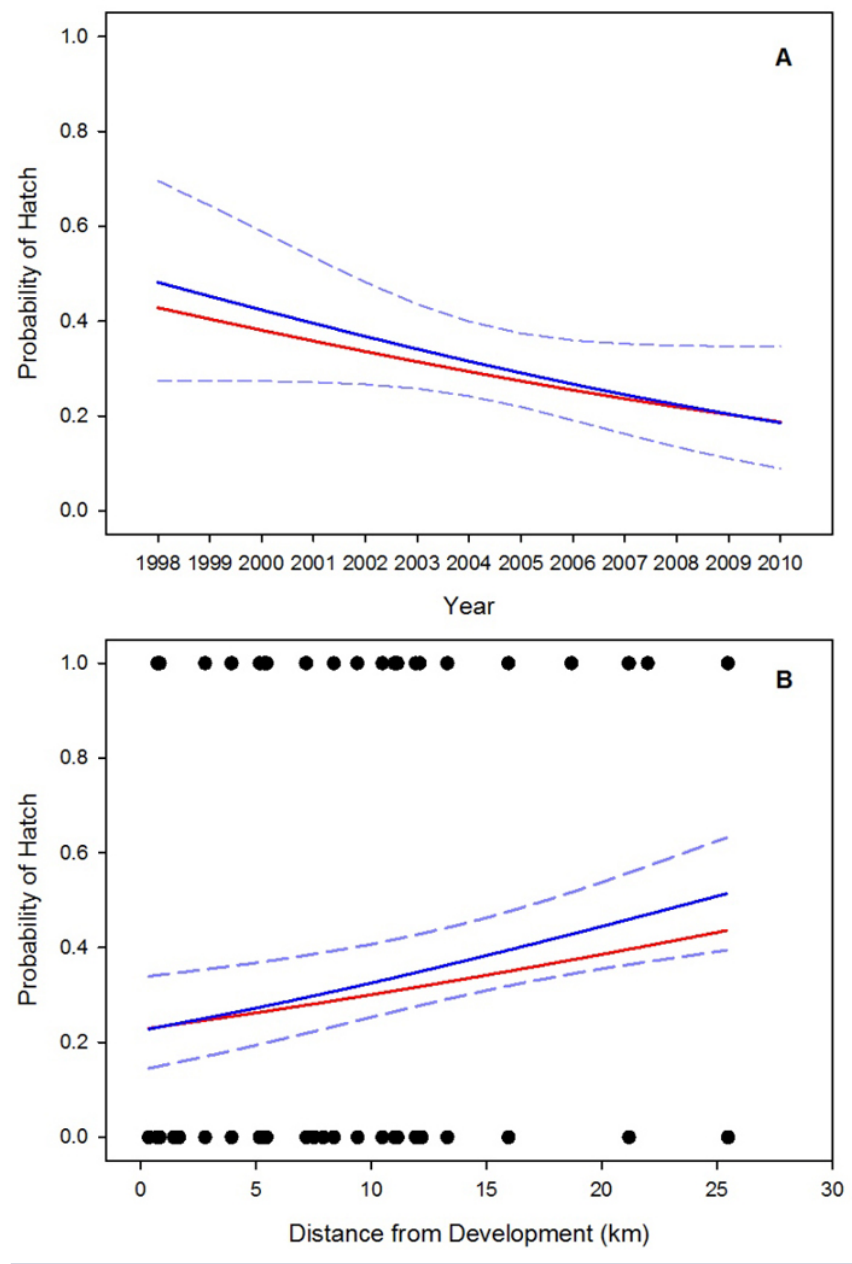

success of nests within the ZOI was not different than zero ( $\beta$ $=-0.04, S E=0.06, Z=-0.68, P=0.50, n=60$ nest-years).

Three nests occurred within ZOI estimated for occupancy (range: $0.8 \mathrm{~km}$ to $5.4 \mathrm{~km}$ ) near Diavik, which provided 11 nestyear observations to test the association between hatch success and mine activity levels. Correlation analysis indicated no association between hatch success and the maximum monthly average number of employees at site $(r=-0.09, P=0.80)$. 
Table 3. Model selection results for the probability of raptor hatch success in the Lac de Gras study area, 1998 to 2010. Shown are model number of model parameters (K), quasiAkaike's Information Criterion score (QAICc) and difference from top model ( $\triangle \mathrm{QAICc})$, and relative model weight $\left(\mathrm{w}_{i}\right)$.

\begin{tabular}{|c|c|c|c|c|}
\hline Model & -log likelihood & KQAICc & $\Delta \mathrm{QAICc}$ & $\mathrm{w}_{i}$ \\
\hline dist + year & -47.95 & 4104.21 & 0.00 & 0.20 \\
\hline year & -49.41 & 3105.00 & 0.79 & 0.14 \\
\hline dist & -49.44 & 3105.06 & 0.85 & 0.13 \\
\hline dist + rain & -48.56 & 4105.41 & 1.20 & 0.11 \\
\hline dist + year + year*dist & -47.59 & 5105.63 & 1.42 & 0.10 \\
\hline dist + habitat & -48.99 & 4106.29 & 2.08 & 0.07 \\
\hline equal means (null) & -51.34 & 2106.77 & 2.56 & 0.06 \\
\hline $\begin{array}{l}\text { dist }+ \text { dist }^{2}+\text { rain }+ \text { habitat } \\
\text { (global) }\end{array}$ & -48.05 & 6108.74 & 4.53 & 0.02 \\
\hline
\end{tabular}

Note: dist $=$ distance $;$ dist $^{2}=$ quadratic distance term; rain $=$ amount of rain during storms from 1 May to date of visit to determine hatch success; year is continuous; $\mathrm{K}$ = number of parameters plus 1 for an intercept and plus 1 for dispersion; only models with $\Delta \mathrm{AICc}<$ than the null are presented; the global model is provided for reference.

\section{DISCUSSION}

The results of this study indicated that sensory disturbance from two operating diamond mines in the Lac de Gras area has likely not had an adverse effect on the abundance and distribution of local falcon populations. Although annually variable, nest occupancy for Peregrine and Gyrfalcons has remained relatively high in our study population throughout the last decade and is consistent with other regions of northern Canada. For example, Franke et al. (2010) reported that nests near Rankin Inlet, Nunavut, averaged 79.2\% occupancy (17.4 of 22 occupied) by Peregrine Falcons during 1982 to 2009. The occupancy rate in the Lac de Gras study area was $81.7 \%$ (95\% CI: $73.7 \%$ to $87.8 \%$ ) during 2000 to 2010 . Earlier studies of birds of prey have demonstrated adverse effects such as avoidance of nests in close proximity to development or lower productivity resulting from abandonment of eggs or young (Bednarz 1984, Holthuijzen et al. 1990). This study indicated that nest occupancy was best explained by the year nests were detected, which we expect represents an index of the historical or long-term age of nest sites in the area. Nests that were detected earlier in the study were more likely and more consistently occupied than those detected more recently. This pattern of use and variability is similar to that found in a 27year study of Peregrine Falcons in Greenland where established nests were of higher quality and more likely and consistently occupied than newer, lower quality sites (Wightman and Fuller 2006). Nests detected earlier in our study also tended to be of higher suitability (i.e., the physical index of elevation above sea level, distance to deep water, and proportion of deep water within a $1 \mathrm{~km}$ radius). Our use of year of initial nest detection as an index of historical age assumes that nest sites did not go undetected. We believe that nest site detection was likely high because the spatial distribution of detected nests includes a variety of suitable sites both near and far from the mines and the high level of annual survey activity that occurred throughout the study area during the falcon breeding season.

The relationship between nest occupancy and distance from the mines indicated that there was an increased and more variable likelihood of Peregrine and Gyrfalcons occupying nests within $5.9 \mathrm{~km}$ of development. However, the spatial pattern of nest site use and variability is largely consistent with the spatial distribution of the nest site suitability index scores in the Lac de Gras area. Wightman and Fuller (2006) found that newly established sites tended to be of lower physical suitability (and quality) and had lower and greater variability in the likelihood of use than older more established sites. Scores of site suitability were not uniformly distributed in the Lac de Gras study area and nest sites more recently detected tended to have lower physical suitability scores, were occupied less frequently and consistently and tended to be closer to the mines. Wightman and Fuller (2006) suggested that new sites of lower suitability and quality increase when the local population increases and high quality sites become saturated, which may be the case in the Lac de Gras study area. Although we lacked the information to correlate suitability scores with fitness benefits, the number of sites has increased and suitability has apparently decreased through time. The likelihood and variability of occupancy and spatial patterns of the nest site suitability index leads us to conclude that the presence of the mines has not negatively altered the perceived suitability of nest sites by Peregrine and Gyrfalcons.

Modeling results indicated that hatch success decreased through time and increased with distance from development in our study area. Of these two variables, the temporal decline had marginally greater support and effect magnitude than did the distance variable although effects were weak. Although a decline in hatch success could result in response to minerelated effects, a similar decline over the last decade has also been reported for falcon nests in an undeveloped area within $75 \mathrm{~km}$ of Lac de Gras, near Daring Lake (J. Virgl, C. Stevens, and D. Coulton, unpublished manuscript). Declines in Peregrine Falcon productivity indices over the last decade have also been reported in Nunavut (Franke et al. 2010). Thus, it is difficult to conclude that the decline detected at Lac de Gras is the sole effect of the mines when reproductive parameters have declined over the same period elsewhere across their Arctic breeding range. There was also some support in our data that hatch success increased with distance from the mines. However, this could be related to the spatial distribution of nest site suitability as described by our physical index, in which the three highest suitability scores occur at the furthest distances. Unfortunately, we cannot distinguish between these two effects but the magnitude of increase for hatch success across space was small. We also failed to detect 
a reduction in hatch success as predicted at near $(<5.9 \mathrm{~km})$ from far $(>5.9 \mathrm{~km})$ sites within an estimated zone of influence for occupancy. Although the distance associated with a response could be different between occupancy and hatch success, this distance we used was greater, and thus more conservative, than $2 \mathrm{~km}$ thresholds reported in the literature for birds of prey (Richardson and Miller 1997, reviewed by Benítez-López et al. 2010). As well, a reduction of hatch success related to temporal expansion of mine footprints or changes in mine activity, as indexed by the number of employees at Diavik, for nest sites in close proximity to Diavik was not detected.

The probability of hatching at least one egg is also a function of nest site selection and the age and experience of breeding pairs. Peregrines are territorial breeders and can demonstrate a despotic distribution where competition with other falcons drive nest site selection behavior (Fretwell and Lucas 1969, Wightman and Fuller 2006). Habitat characteristics that provide protection of the nest from weather variables and predation, and close proximity to hunting areas are factors influencing the quality of nest sites (Sergio et al. 2004, Wightman and Fuller 2006). We assume that there are implicit features of a nest site and attributes of breeding pairs that explain a large amount of variation in nest occupancy and hatch success in the study area. The consistency of spatial patterns between nest occupancy rates and our site suitability index supports this assumption but we lack data from marked individuals to assess breeding pair quality. However, if fitness attributes of breeding pairs had not influenced hatch success we would have expected the spatial pattern of success to closely match that of site suitability scores, which was not the case. In general, there was a high degree of variability in the annual use and hatch success of nest sites in the Lac de Gras area as indicated by the uncertainty in model selection results. A large amount of variability in nest site use and hatch success might occur if there are a high number of individuals that move among nests sites within and outside of the study area. Recent findings on Gyrfalcons indicates that regional breeding area fidelity is high but nest site fidelity is low (Booms et al. 2011), one of the two species included in our study. Wightman and Fuller (2006) also suggested that high variability in hatch success might arise as Peregrine Falcons establish nests at low quality sites in years when populations are larger and quality sites become saturated. Thus, the high degree of variability in nest site use and success that we detected may be related partially to the species composition and/or abundance of falcons in the Lac de Gras study area.

Increased precipitation or severe weather events have been shown to reduce productivity of birds of prey (Olsen and Olsen 1989, Bradley et al. 1997, McDonald et al. 2004). Bradley et al. (1997) found that fewer eggs were laid in stormier years and chick mortality was positively correlated with storm event precipitation. Presumably, inclement weather can increase the costs of thermoregulation and make foraging more difficult for adults, thereby reducing the likelihood of successfully raising chicks until fledged. As well, recent findings by Anctil (2012) indicate that rain showers of at least $6 \mathrm{~mm}$ can increase nestling mortality. In the present study, the estimate for the effect of rainfall on hatch success was negative; however, occupancy and hatch success at nest sites was variable enough among years that precision was poor. Interestingly, Peregrine and Gyrfalcons in our study had above average hatch success during 2002 and 2006 when storm rainfall was considerably above average. During these two years $68 \%$ and $54 \%$ of accumulated rainfall occurred during single storms in late June and early July, respectively. Apparently the adults breeding in the study area during these two years were able to withstand and/or recover from these natural disturbance events and successfully produce chicks. In addition to total rainfall, the frequency or duration of storms may also be important. Poor weather conditions have been shown to reduce Peregrine Falcon nest site productivity in other areas of Arctic Canada (Bradley et al. 1997, Anctil 2012). Based on the evidence from other studies, we predict that inclement weather has a negative influence on falcon populations in the Lac de Gras area even though we did not detect a statistically significant relationship between spring-summer storm events and hatch success.

Nest use and hatch success rates are also closely associated with prey abundance. Peregrine Falcons depend primarily on avian prey including waterbirds, shorebirds, songbirds, and ptarmigan (White et al. 2002, Dawson et al. 2011). However, microtine rodents, including lemmings and voles, can account for as much as 20\% of Peregrine Falcon diets during nonpeak years of microtine abundance (Bradley and Oliphant 1991). Breeding Bird Survey data collected at Ekati during 2004 to 2010 suggests that avian prey species may have declined during this period but these data were not correlated with annual patterns of falcon nest use or hatch success over the same period. As well, annual relative abundance of small mammal prey was not correlated with nest use or hatch success. A long-term study of Peregrine Falcons in the Keewatin district of Nunavut found a dramatic increase in the density of Peregrines in a year with peak microtine rodent abundance (Court et al. 1988). Higher reproductive performance in that year suggested that the use of lemmings by Peregrine Falcons might be significant in some years. We found that the success of nests was unrelated to small mammal abundance, which differs from findings of other studies. This difference could arise if local microtine populations in the study area are not synchronized with the population cycles at Daring Lake. We expect that our assumption of synchrony between Lac de Gras and Daring Lake study area is reasonable because the study areas have similar habitat composition and are adjacent to one another. However, we lack empirical data to evaluate this assumption. 


\section{CONCLUSION}

The temporal decline in hatch success detected at Lac de Gras cannot be assumed to have been caused by indirect habitat effects from the Ekati and Diavik diamond mines. Peregrines and Gyrfalcons are also monitored for hatch success at nearby Daring Lake, where no industrial development exists, and hatch success there has declined similarly over the same period (J. Virgl, C. Stevens, and D. Coulton, unpublished manuscript). Also supporting this conclusion, we found no relationship between annual hatch success and expansion of mine footprints for nests within $5.9 \mathrm{~km}$. There was also no association between hatch success of nests within $5.9 \mathrm{~km}$ of Diavik and this mine's activity levels. However, our activity index may not fully capture the level of disturbance perceived by falcons. Declines in falcon hatch success and productivity indices during the last decade have also been reported at nearby Snap Lake Mine (C. De La Mare and D. Coulton, unpublished manuscript) and other areas in Arctic Canada (Franke et al. 2010). A 22\% temporal decline in chick productivity of Peregrine Falcons near Rankin Inlet during the same period as our study was postulated to have been caused by severe weather (Franke et al. 2010). The temporal trend observed could also be related to the addition of lower quality sites through time. Although we failed to find relationships between prey abundance and weather, the patterns of nest use and hatch success are likely to have been correlated with environmental variables we did not measure or could not measure with greater precision. Collectively the lines of evidence analyzed in our study indicate that patterns of hatch success at Lac de Gras are consistent with the hypothesis that observed temporal declines in falcon productivity may be in response to natural environmental conditions occurring at larger geographic scales.

Responses to this article can be read online at:

http://www.ace-eco.org/issues/responses.php/621

\section{Acknowledgments:}

We thank Diavik Diamond Mines Inc. (Diavik) and BHP Billiton Canada Inc. and their Environment stafffor collecting and providing access to the raptor and GIS data, and Diavik for data on employees at site. Thanks also to S. Carriére of Environment Natural Resources, Government Northwest Territories, for use of small mammal data from Daring Lake. We thank Golder Associates Ltd. for in-kind contributions and D. Clake for GIS support. Finally, we thank L. Dagenais, P. Fast and C. Stevens, R. Norris, and three anonymous reviewers for comments to improve an earlier draft of this manuscript.

\section{LITERATURE CITED}

Aitken, K. E. H., K. L. Wiebe, and K. Martin. 2002. Nest site reuse patterns for a cavity-nesting bird community in interior British Columbia. Auk 119:391-402.

Ammon, E. M., and P. B. Stacey. 1997. Avian nest success in relation to past grazing regimes in a montane riparian system. Condor 99:7-13. http://dx.doi.org/10.2307/1370219

Anctil, A. 2012. Effects of summer precipitation on peregrine falcons (Falco peregrinus) breeding in the Arctic. Thesis, University of Québec at Rimouski, Québec, Canada.

Arnold, T. W. 2010. Uninformative parameters and model selection using Akaike's Information Criterion. Journal of Wildlife Management 76:1175-1178.

Bednarz, J. C. 1984. The effect of mining and blasting on breeding prairie falcon (Falco mexicanus) occupancy in the Caballo Mountains, New Mexico. Raptor Research 8:16-19.

Benítez-López, A., R. Alkemade, and P. Verweij. 2010. The impacts of roads and other infrastructure on mammal and bird populations: a meta-analysis. Biological Conservation 143:1307-1316. http://dx.doi.org/10.1016/j.biocon.2010.02.009

Bradley, M., R. Johnstone, G. Court, and T. Duncan. 1997. Influence of weather on breeding success of Peregrine Falcons in the Arctic. Auk 114:786-791. http://dx.doi.org/10.2307/4089303

Bradley, M., and L. W. Oliphant. 1991. The diet of Peregrine Falcons in Rankin Inlet, Northwest Territories: an unusually high proportion of mammalian prey. Condor 93:193-197. http://dx.doi.org/10.2307/1368628

Booms, T. L., S. L. Talbot, G. K. Sage, B. J. McCaffery, K. G. McCracken, and P. F. Schempf. 2011. Nest-site fidelity and dispersal of Gryfalcons estimated by noninvasive genetic sampling. Condor 113:768-778. http://dx.doi.org/10.1525/ cond.2011.100178

Boulanger, J., K. G. Poole, A. Gunn, and J. Wierzchowski. 2012. Estimating the zone of influence of industrial developments on wildlife: a migratory caribou Rangifer tarandus groenlandicus and diamond mine case study. Wildlife Biology 18:164-179. http://dx.doi.org/10.2981/11-045

Burnham, K. P., and D. R. Anderson. 2002. Model selection and multimodel inference: a practical information-theoretic approach. Second edition. Springer Verlag, New York, New York, USA.

Court, G. S., C. G. Gates, and D. A. Boag. 1988. Natural history of the Peregrine Falcon in the Keewatin District of the Northwest Territories. Arctic 41:17-30.

Craighead, F. C., Jr., and D. P. Mindell. 1981. Nesting raptors in western Wyoming, 1947 and 1975. Journal of Wildlife Management 45:865-872. http://dx.doi.org/10.2307/3808095 
Dawson, R. D., D. H. Mossop, and B. Boukall. 2011. Prey use and selection in relation to reproduction by Peregrine Falcons breeding along the Yukon River, Canada. Journal of Raptor Research 45:27-37. http://dx.doi.org/10.3356/JRR-09-84.1

Ecological Stratification Working Group. 1998. A national ecological framework for Canada. Agriculture and Agri-Food Canada, Research Branch Centre for Land and Biological Resources Research and Environment Canada, State of the Environment Directorate, Ecozone Analysis Branch, Hull, Québec, Canada.

Franke, A., M. Setterington, G. Court, and D. Birkholz. 2010. Long-term trends of persistent organochlorine pollutants, occupancy and reproductive success in peregrine falcons (Falco peregrinus tundrius) breeding near Rankin Inlet, Nunavut, Canada. Arctic 63:452-450.

Fretwell, S. D., and H. L. Lucas Jr. 1969. On territorial behavior and other factors influencing habitat distribution in birds. Acta Biotheoretica 19:16-36. http://dx.doi.org/10.1007/ $\underline{\mathrm{BF} 01601953}$

Government of Canada. 2002. Species at Risk Act. S.C, 2002, c. 29. Government of Canada, Ottawa, Ontario, Canada.

Government of the Northwest Territories (GNWT). 2012. Species at Risk in the Northwest Territories. GNWT, Yellowknife, NWT, Canada.

Holthuijzen, A. M. E., W. G. Eastland, A. R. Ansell, M. N. Kochert, R. D. Williams, and L. S. Young. 1990. Effects of blasting on behaviour and productivity of prairie nesting falcons. Wildlife Society Bulletin 18:270-281.

Jackson, D. A. 1993. Stopping rules in principal components analysis: a comparison of heuristical and statistical approaches. Ecology 74:2204-2214. http://dx.doi. org/10.2307/1939574

Johnson, C. J., M. S. Boyce, R. L. Case, H. D. Cluff, R. J. Gau, A. Gunn, and R. Mulders. 2005. Cumulative effects of human developments of arctic wildlife. Wildlife Monographs 160:1-36.

Kaisanlahti-Jokimäki, M., J. Jokimäki, E. Huhta, M. Ukkola, P. Helle, and T. Ollila. 2008. Territory occupancy and breeding success of the Golden Eagle (Aquila chrysaetos) around tourist destinations in northern Finland. Ornis Fennica 85:2-12.

Kirk, D. A., K. A. Lindsay, and R. W. Brook. 2011. Risk of agricultural practices and habitat change to farmland birds. Avian Conservation and Ecology 6(1): 5. http://dx.doi. org/10.5751/ACE-00446-060105

Littell, R. C., W. W. Stroup, and R. J. Freund. 2002. $S A S^{\circledast}$ for linear models. Fourth edition. SAS Institute, Inc. Cary, North Carolina, USA.
Matthews, S., and H. Epp. 2001. Vegetation classification for the West Kitikmeot/Slave Study Region. Final report submitted to the West Kitikmeot/Slave Study Society by the Department of Resources, Wildlife and Economic Development, Government of the Northwest Territories. Yellowknife, Northwest Territories, Canada.

McDonald, P. G., P. D. Olsen, and A. Cockburn. 2004. Weather dictates reproductive success and survival in the Australian Brown Falcon (Falco berigora). Journal of Animal Ecology 73:683-692. http://dx.doi.org/10.1111/ j.0021-8790.2004.00842.x

Natural Resources Canada. 2001. Canada 3D. Centre for Topographic Information, Sherbrook, Québec, Canada. [online] URL: http://geogratis.gc.ca/geogratis/search?lang= en

Olsen, P. D., and J. Olsen. 1989. Breeding of Peregrine Falcons (Falco peregrinus). III. Weather, nest quality, and breeding success. Ети 89:6-14. http://dx.doi.org/10.1071/MU9890006

Palmer, A. G., D. L. Nordmeyer, and D. D. Roby. 2003. Effects of jet aircraft overflights on parental care of peregrine falcons. Wildlife Society Bulletin 31:499-509.

Pavel, V. 2004. The impact of grazing animals on nesting success of grassland passerines in farmland and natural habitats: a field experiment. Folia Zoologica 53:171-178.

Polfus, J. L., M. Hebblewhite, and K. Heinmeyer. 2011. Identifying indirect habitat loss and avoidance of human infrastructure by northern mountain woodland caribou. Biological Conservation 144:2637-2646. http://dx.doi. org/10.1016/j.biocon.2011.07.023

Poole, K. G., and R. G. Bromley. 1988. Interrelationships within a raptor guild in the central Canadian Arctic. Canadian Journal of Zoology 66:2275-2282. http://dx.doi.org/10.1139/ z88-338

R Development Core Team. 2012. R: a language and environment for statistical computing. $\mathrm{R}$ Foundation for Statistical Computing, Vienna, Austria. ISBN 3-900051-07-0. [online] URL: http://www.R-project.org

Richardson, C. T., and C. K. Miller. 1997. Recommendations for protecting raptors from human disturbance: a review. Wildlife Society Bulletin 25:634-638.

Sergio, F., F. Rizzolli, L. Marchesi, and P. Pedrini. 2004. The importance of interspecific interactions for breeding-site selection: Peregrine Falcons seek proximity to Raven nests. Ecography 27:818-826. http://dx.doi.org/10.1111/ j.0906-7590.2004.04030.x 
Steenhof, K., M. N. Kochert, L. B. Carpenter, and R. N. Lehman. 1999. Long-term Prairie Falcon population changes in relation to prey abundance, weather, land uses, and habitat conditions. Condor 101:28-41. http://dx.doi.org/10.2307/1370443

Venables, W. N., and B. D. Ripley. 2002. Modern applied statistics with S. Fourth edition, Springer, New York, New York, USA. http://dx.doi.org/10.1007/978-0-387-21706-2

Weir, J. N., S. P. Mahoney, B. McLauren, and S. H. Ferguson. 2007. Effects of mine development on woodland caribou Rangifer tarandus distribution. Wildlife Biology 13:66-74. http://dx.doi.org/10.2981/0909-6396(2007)13[66:EOMDOW] 2.0.CO;2

White, C. M., N. J. Clum, T. J. Cade, and W. G. Hunt. 2002. Peregrine Falcon (Falco peregrinus). In A. Poole and F. Gill, editors. Birds of North America, Number 660. Academy of Natural Sciences, Philadelphia, Pennsylvania, USA, and American Ornithologists' Union, Washington, D.C., USA. [online] URL: http://bna.birds.cornell.edu/bna/species/660/ articles/introduction

White, C. M., and T. L. Thurow. 1985. Reproduction of the Ferruginous Hawks exposed to controlled disturbance. Condor 87:14-22. http://dx.doi.org/10.2307/1367125

Wightman, C. S., and M. R. Fuller. 2005. Spacing and physical selection patterns of Peregrine Falcons in central west Greenland. Wilson Bulletin 117:226-236. http://dx.doi. org/10.1676/04-036.1

Wightman, C. S., and M. R. Fuller. 2006. Influence of habitat heterogeneity on distribution, occupancy patterns, and productivity of breeding Peregrine Falcons in central west Greenland. Condor 108:270-281. http://dx.doi.org/10.1650/0010-5422 (2006)108[270:IOHHOD]2.0.CO;2 